\title{
Short-Term Afferent Axotomy Increases Both Strength and Depression at la-Motoneuron Synapses in Rat
}

\author{
Kevin L. Seburn and Timothy C. Cope \\ Emory University Medical School, Department of Physiology, Atlanta, Georgia 30322
}

Synaptic efficacy at the rat la-motoneuron synapse has been reported to increase in vivo, within $3 \mathrm{~d}$ of sectioning a single muscle nerve (Miyata and Yasuda, 1988). We provide an indirect test of the hypothesis that this increase is caused by altered probability of transmitter release of axotomized afferents. Experiments consisted of in vivo recording of maximal composite group I EPSPs evoked in intact rat medial gastrocnemius (MG) motoneurons by stimulation of the lateral gastrocnemius-soleus nerve (LG-S). We compared the maximal LG-S EPSP amplitude and the response to high-frequency stimulation (modulation) recorded in untreated rats, with the same measures recorded in rats that had the LG-S nerve axotomized $3 \mathrm{~d}$ before data collection. In confirmation of previous work, the mean amplitude of LG-S EPSPs evoked by stimulation of axotomized afferents was significantly larger than that measured in untreated rats $(3.9 \pm 0.34$ and $2.3 \pm 0.19 \mathrm{mV}$, respectively). The increase in EPSP amplitude was accompanied by significantly greater negative modulation (depression) of EPSP amplitude during high-frequency stimulation (-39 \pm $4 \%$ and $-53 \pm 4 \%$, untreated and treated, respectively). Modulation would not be expected to change if the increase in EPSP amplitude was attributable solely to a greater number of afferent connections (Koerber and Mendell, 1991). Therefore, the present results are consistent with the hypothesis that the initial axotomy-induced increase in synaptic efficacy occurs because of an increase in the probability of transmitter release. Furthermore, these results suggest that the probability of transmitter release at this synapse is regulated by either afferent activity and/or trophic communication with the target muscle.

Key words: la afferent; synaptic plasticity; axotomy; monosynaptic; probability of transmitter release; rat; motoneuron; synaptic efficacy; activity; synaptic depression
Short and long-term changes in synaptic efficacy occur in vivo at the central synapse between muscle spindle afferents (Ia) and spinal motoneurons (Mendell, 1984). However, our knowledge of the specific mechanisms controlling efficacy at this synapse, and indeed most CNS synapses in the intact organism, is incomplete.

Changes in afferent function at the Ia-motoneuron synapse have frequently been studied after chronic axotomy ( $>2$ weeks). These studies consistently show that the amplitude of the group I EPSP measured in intact motoneurons decreases after chronic nerve section (Eccles et al., 1959; Goldring et al., 1980; Mendell et al., 1995; Munson et al., 1997). However, this decrease in synaptic efficacy is not immediate, and the initial response (1-5 d) to peripheral nerve axotomy is actually an increase in Ia EPSP amplitude measured in normal motoneurons (Miyata and Yasuda, 1988).

The mechanisms of this initial axotomy-induced increase in synaptic efficacy have not been investigated but are of interest for several reasons. First, evidence indicates that the early increase is related to decreased afferent impulse activity (Miyata and Yasuda, 1988; Manabe et al., 1989). Second, axotomy eliminates access to trophic factors supplied by the muscle. This fact is of particular

\footnotetext{
Received Sept. 5, 1997; revised Nov. 7, 1997; accepted Nov. 11, 1997.

This research was supported by the National Institute of Neurological Disorders and Stroke Grant NS31563. We extend special thanks to Dr. Martin Pinter for his reading and critique of this manuscript. We also acknowledge the assistance of Eleanor Feingold with statistical analyses and the secretarial assistance of Katie Swanson.

Correspondence should be addressed to Dr. Kevin L. Seburn, Emory University Medical School, Department of Physiology, 1648 Pierce Drive, Room 236, Atlanta, GA 30322.

Copyright (C) 1998 Society for Neuroscience $\quad 0270-6474 / 98 / 181142-06 \$ 05.00 / 0$
}

interest given recent findings regarding the neurotrophins, brainderived neurotrophic factor (BDNF), neurotrophin-3 (NT-3), and neurotrophin-4 (NT-4) (Lewin and Barde, 1996). These factors are present in the muscle, are retrogradely transported to the spinal cord (Distefano et al., 1992), and have recently been implicated in the regulation of synaptic function at the Ia-motoneuron synapse (Munson et al., 1997) and elsewhere in the CNS of adult mammals (Kang and Schuman, 1995a,b).

In light of these considerations, we have examined synaptic function after short-term axotomy using a stimulation paradigm that reveals correlated differences between Ia EPSP amplitude and amplitude modulation during high-frequency stimulation. Specifically, large EPSPs tend to show more negative modulation (depression) than do small EPSPs (Collins et al., 1984, 1986; Koerber and Mendell, 1991; Mendell et al., 1995). In addition, amplitude modulation of composite EPSPs is similar to single fiber EPSP modulation (Koerber and Mendell, 1991), and therefore an increase in EPSP amplitude resulting from a greater number of afferent connections would not predict a change in high-frequency amplitude modulation. On the basis of these findings and other work at the Ia-motoneuron synapse (Kuno, 1964a,b; Hirst et al., 1981; Peshori et al., 1998) and by inference from more direct measures in other systems (Del Castillo and Katz, 1954; Dobrunz and Stevens, 1997), the variation in highfrequency amplitude modulation across motoneurons has been interpreted as reflecting differences in the probability of transmitter release.

Thus, we hypothesized that if the axotomy-induced increase in EPSP amplitude occurs because of altered probability of transmitter release, consequent to decreased impulse traffic and/or the absence of trophic support, then short-term axotomized afferents, 
producing enlarged EPSPs, should show greater negative modulation with high-frequency stimulation (Peshori et al., 1998).

\section{MATERIALS AND METHODS}

Male Sprague Dawley rats (250-350 gm) (Harlan Sprague Dawley, Birmingham, AL) were assigned randomly either to a control or $3 \mathrm{~d}$ treatment group (14 rats/group). All rats were housed in similar conditions with a 12/12 hr dark/light cycle and were allowed food and water ad libitum.

Axotomy. Rats assigned to the treatment group were anesthetized (ketamine and xylazine, 90 and $10 \mathrm{mg} / \mathrm{kg}$, respectively, i.p.) and then underwent surgery to expose and transect the left lateral gastrocnemiussoleus (LG-S) muscle nerve. The cut nerve was ligated (6.0 silk), and the proximal end was deflected onto the fat pad in the tibial fossa to prevent reinnervation and to limit access to trophic factors present in skin or muscle.

Acute surgical preparation. Three days after the survival surgery, anesthesia was induced in rats by intraperitoneal injection of a ketamine and xylazine mixture ( 90 and $10 \mathrm{mg} / \mathrm{kg}$, respectively) and then maintained by chronic venous infusion $(0.8-1.6 \mathrm{ml} / \mathrm{hr})$ of a ketamine and xylazine mixture diluted in Ringer's solution and dextrose (9.6 and 1.1 $\mathrm{mg} / \mathrm{ml}$, ketamine and xylazine, respectively). A carotid catheter was inserted for monitoring of arterial blood pressure (maintained at $\geq 65$ $\mathrm{mmHg}$ ), and a tracheotomy permitted maintenance of end-tidal $\mathrm{CO}_{2}$ at $\sim 4 \%$ by adjusting the level of anesthesia and/or artificial ventilation $(60-80$ breaths $/ \mathrm{min})$. Body temperature was monitored and maintained at $37 \pm 1^{\circ} \mathrm{C}$ using a heating pad and/or infrared heating lamp.

Next, the left common peroneal and sural nerve branches were cut distally and separated from the tibial nerve as far proximally as possible. The medial gastrocnemius (MG) and LG-S nerve branches were transected and ligated (6.0 silk). The remaining portion of the tibial nerve was then crushed at the most distal point to prevent muscle contraction during stimulation. Finally, the dorsal laminae of vertebrae S1-T10 were exposed, and the animal was moved to a stereotaxic frame.

Data collection setup. The spinal column was secured in specially designed vise clamps (Gonzalez and Collins, 1997). A laminectomy was performed (T12-L6), the dura was cut, and the dorsal roots were deflected to allow access to the lumbar enlargement.

A bipolar stimulating electrode was placed on the tibial, LG-S, and MG nerve branches. A monopolar ball electrode was placed in contact with dorsal roots. The dorsal root volley was used to initially set the stimulation intensity at $2-2.5 \times$ threshold $(500 \mu$ sec pulse duration).

Intracelluar recording. Conventional intracellular recording techniques were used to obtain measurements from MG motoneurons using glass microelectrodes $(1.2 \mathrm{~mm}$ outer diameter $)$ filled with $2 \mathrm{M}$ potassium citrate and input resistances between 10 and $18 \mathrm{M} \Omega$. Only cells with a stable resting membrane potential $(-50 \mathrm{mV}$ or greater) and an antidromic spike $\geq 68.5 \mathrm{mV}$ were accepted for analysis. With these conditions met, the composite EPSPs produced by stimulation of the LG-S nerve were studied at three stimulation frequencies as shown in Figure 1. EPSPs evoked with single pulses delivered at $0.5 \mathrm{~Hz}$ and trains of five stimuli delivered at $18 \mathrm{~Hz}$ were averaged over 10-50 stimulus repetitions. In all cases, stimulus intensities of $2-2.5 \times$ group I threshold elicited the maximal monosynaptic EPSP. Finally, modulation of EPSP amplitude was studied using the paradigm of Mendell and colleagues (e.g., Davis et al., 1985; Peshori et al., 1998); trains of 32 stimuli delivered at $167 \mathrm{~Hz}$ were repeated every $2 \mathrm{sec}$ and averaged over 10-50 trials. At the end of each of these stimulus trains, three single stimulus pulses were presented 100, 150, and $200 \mathrm{msec}$ later. In a few cases, the potentiation of EPSPs early in the high-frequency trains elicited action potentials that prevented measurement of EPSP amplitude. In these cases, stimulus strength was reduced slightly to subthreshold levels. It is unlikely that this procedure affected our measurements because varying stimulus strength was tested at several synapses and found to have no detectable effect on modulation behavior. After study of synaptic potentials, the motoneurons were characterized by the following measures (see Gardiner, 1993): (1) repeated measures of rheobase current (150 msec current pulse), (2) afterhyperpolarization (AHP) amplitude and half-decay time, and (3) input resistance (IR) by the spike-height method (Frank and Fuortes, 1956) using hyperpolarizing and depolarizing current pulses of 0.5 and 1 $\mathrm{nA}$. These measures were incomplete for some motoneurons because of electrode rectification or deterioration of the recording. Data were amplified $(\times 1000)$ and filtered $(\mathrm{DC}$ to $10 \mathrm{kHz})$ and then digitized and collected at a sampling rate of $22 \mathrm{kHz}$ using personal computer-based software (Cambridge Electronics Design). a

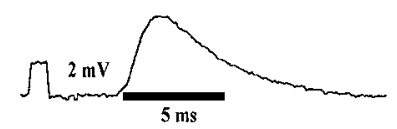

c

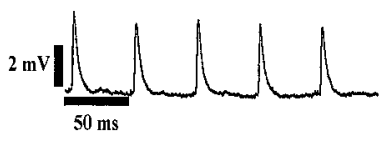

e

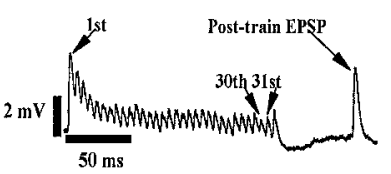

b

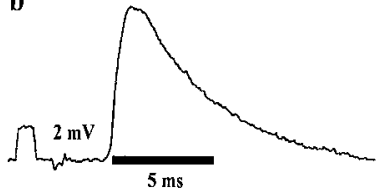

d

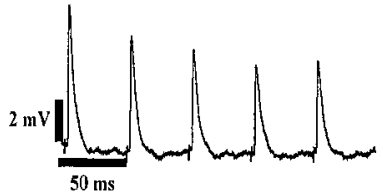

f

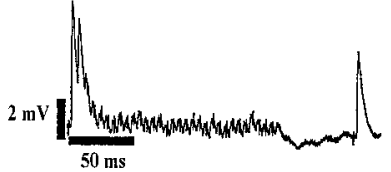

Figure 1. Raw data traces showing LG-S EPSPs recorded at maximal group I strength in MG motoneurons. Traces show EPSPs recorded with a single pulse at $0.5 \mathrm{~Hz}(a, b)$ and during an $18 \mathrm{~Hz}$ pulse train (five pulses repeated every $2 \mathrm{sec})(c, d)$ and a $167 \mathrm{~Hz}$ pulse train $(32$ pulses repeated every $2 \mathrm{sec})(e, f)$. EPSPs were recorded from comparable cells (see below) in untreated $(a, c, e)$ and 3 -d-axotomized $(b, d, f)$ rats. Traces are representative of the observed mean effects of short-term axotomy, increased EPSP amplitude ( $a$ vs $b$ ) and increased negative modulation at 18 and $167 \mathrm{~Hz}$ ( $c$ vs $d$ and $e$ vs $f$, respectively). $a, c, e$ (Untreated), EPSP amplitude $=4.8 \mathrm{mV}$, motoneuron $\mathrm{CV}=40 \mathrm{~m} / \mathrm{sec}$, rheobase $=2.9 \mathrm{nA}$, $\mathrm{IR}=2.0 \mathrm{M} \Omega$, AHP amplitude $=2.7 \mathrm{mV}$, and AHP half-decay time $=$ 26.0 msec. $b, d, f(3 \mathrm{~d}$ axotomy), EPSP amplitude $=9.3 \mathrm{mV}$, motoneuron $\mathrm{CV}=33 \mathrm{~m} / \mathrm{sec}$, rheobase $=5.3 \mathrm{nA}, \mathrm{IR}=3.9 \mathrm{M} \Omega$, , AHP amplitude $=3.4$ $\mathrm{mV}$, and AHP half-decay time $=23.0 \mathrm{msec}$.

Measurement of frequency-related behavior. Preliminary experiments were performed to examine the response of EPSP amplitude to a range of frequencies $(0.1,0.5,1.0,10,18,36,100,167$, and $250 \mathrm{~Hz})$. Several observations from this preliminary work are relevant. (1) In agreement with previous work showing that the rat monosynaptic reflex is particularly sensitive to frequency-related depression (Kaizawa and Takahashi, 1970; Seburn and Cope, 1997), we observed depression in most cells at frequencies of $>1 \mathrm{~Hz}$. (2) In both treated and untreated animals, mean EPSP amplitude measured at $18 \mathrm{~Hz}$ was significantly reduced (approximately $-20 \%$ ) relative to mean amplitude measured at $0.5 \mathrm{~Hz}$. (3) At frequencies of $18 \mathrm{~Hz}$ or greater, the response was variable, with most cells showing negative modulation but some showing positive modulation. On the basis of these observations, we chose to use the maximum EPSP amplitude evoked by single pulses at $0.5 \mathrm{~Hz}$ as our control EPSP. Monosynaptic EPSP amplitude was determined from the earliest peak in the postsynaptic potential evoked at stimulus strengths of 2-2.5 $\times$ threshold. This peak was always within the limits of monosynaptic delay and easily discernible. To allow comparison with previous work in the cat (Collins et al., 1984; Koerber and Mendell, 1991; Mendell et al., 1995) and the rat (Peshori et al., 1998), we determined high-frequency modulation measurements using $167 \mathrm{~Hz}$ stimulation. The modulation ratio at $167 \mathrm{~Hz}$ was calculated as follows (see Fig. 1e):

$167 \mathrm{~Hz}$ modulation $(\%)=100\left[\left[\frac{(\text { EPSP30 }+ \text { EPSP31 }) \div 2}{\text { EPSP1 }}\right]-1\right]$.

Measurements of EPSPs within the $167 \mathrm{~Hz}$ burst (30th, 31st) were corrected for the contribution of summation of these EPSPs with the falling phase of the EPSP preceding it (see Collins et al., 1984; Peshori et al., 1998). Because of the depression observed at $18 \mathrm{~Hz}$, we also compared the effects of axotomy on the response with $18 \mathrm{~Hz}$ stimulation by calculating the following ratio (see Fig. $1 c$ ) : $18 \mathrm{~Hz}$ modulation ratio = (average of last four EPSPs in $18 \mathrm{~Hz}$ train)/(control EPSP amplitude).

Persistent effects of the high-frequency stimulus train $(167 \mathrm{~Hz})$ were evaluated from the amplitude of EPSPs evoked at $100 \mathrm{msec}$ and at $2 \mathrm{sec}$ 


\begin{tabular}{|c|c|c|c|c|c|c|}
\hline & \multicolumn{3}{|c|}{ Untreated } & \multicolumn{3}{|c|}{3 d axotomy } \\
\hline & $n$ & Mean $\pm \mathrm{SE}$ & Range & $n$ & Mean $\pm \mathrm{SE}$ & Range \\
\hline Conduction velocity (m/sec) & 46 & $49.9 \pm 1.2$ & $28.9-62.5$ & 45 & $48.3 \pm 1.2$ & $28.3-61.3$ \\
\hline Action potential amplitude $(\mathrm{mV})$ & 46 & $79.3 \pm 1.2$ & $68.5-93.9$ & 45 & $78.3 \pm 0.9$ & $68.5-92.9$ \\
\hline Rheobase current (nA) & 41 & $7.6 \pm 0.80$ & $2.1-24.0$ & 38 & $8.2 \pm 0.82$ & $1.5-20.6$ \\
\hline Input resistance $(\mathrm{M} \Omega)$ & 19 & $1.6 \pm 0.22$ & $0.40-4.1$ & 28 & $1.8 \pm 0.23$ & $0.22-5.2$ \\
\hline AHP amplitude (mV) & 29 & $1.7 \pm 0.21$ & $0.28-3.9$ & 34 & $1.9 \pm 0.13$ & $0.79-4.1$ \\
\hline AHP decay (msec) & 29 & $15.7 \pm 1.1$ & $5.6-31.7$ & 34 & $15.9 \pm 0.96$ & $8.1-34.8$ \\
\hline EPSP amplitude $(\mathrm{mV})^{*}$ & 46 & $2.3 \pm 0.19$ & $0.25-5.7$ & 45 & $3.9 \pm 0.34$ & $0.79-9.7$ \\
\hline $167 \mathrm{~Hz}$ modulation $(\%)^{*}$ & 39 & $-39.0 \pm 4.0$ & $-79.0-24.0$ & 43 & $-53.0 \pm 4.0$ & $-96.0-3.0$ \\
\hline $18 \mathrm{~Hz}$ modulation ratio* & 43 & $0.88 \pm 0.03$ & $0.46-1.4$ & 42 & $0.79 \pm 0.02$ & $0.61-1.2$ \\
\hline $2 \mathrm{sec}$ post-train ratio & 39 & $1.0 \pm 0.03$ & $0.71-1.6$ & 43 & $0.98 \pm 0.02$ & $0.61-1.4$ \\
\hline $0.1 \mathrm{sec}$ post-train ratio & 39 & $0.99 \pm 0.04$ & $0.65-1.7$ & 43 & $0.91 \pm 0.03$ & $0.51-1.4$ \\
\hline
\end{tabular}

*Significant difference $(p<0.05)$ between untreated and $3 \mathrm{~d}$ axotomy value.

after the train. The longer time delay was obtained from the averaged record of the first EPSP in repeating $167 \mathrm{~Hz}$ trains, because this EPSP reoccurred in repeated trains with a time delay of $2 \mathrm{sec}$ after each preceding train. The ratios were calculated as follows (see Fig. 1e): $2 \mathrm{sec}$ post-train ratio $=(1$ st EPSP in $167 \mathrm{~Hz}$ train $) /($ control EPSP amplitude $)$ and $0.1 \mathrm{sec}$ post-train ratio $=$ (postburst EPSP amplitude) $/($ control EPSP amplitude).

Afferent activity. Two additional experiments were performed to determine the extent of activity in axotomized afferents 1 and $3 \mathrm{~d}$ after sciatic nerve section. The general experimental setup was as described above. Afferent axons were penetrated in the L4-L5 dorsal roots using glass microelectrodes and were identified as sciatic afferents by the presence of an orthodromic action potential generated by stimulating the sciatic nerve at $4-5 \times$ group I threshold. Action potentials were recorded to determine conduction velocity, and then stimulation was discontinued for $60 \mathrm{sec}$ to determine whether the afferent was silent or spontaneously active. Seventy-five afferents were sampled from each of two rats. Previous work has shown that afferents with a conduction velocity greater than $\sim 40 \mathrm{~m} / \mathrm{sec}$ are either group I or II and that the majority $(88 \%)$ of these respond to muscle stretch (Lewin and McMahon, 1991).

Statistics. Values are reported as mean \pm SE unless otherwise indicated. A nested ANOVA was used to test for a treatment effect (axotomy). Animal-to-animal variation was treated as a random effect. This analysis accounts for the effect of taking a small number of measures from several animals and using them to represent a single population. Correlation coefficients were calculated using the Pearson product-moment correlation. A probability value of $<0.05$ was used as a limit for declaring statistical significance.

\section{RESULTS}

Sectioning of the LG-S muscle nerve had no detectable effect on the properties of the intact MG neurons (Table 1). The ranges for passive motoneuron properties measured in axotomized and untreated rats were similar, and mean values were not different for any measure $(F=0.06-1.1 ; p=0.29-0.87)$.

Comparison of the mean composite LG-S EPSP amplitudes evoked in intact MG motoneurons by maximal group I stimulation showed that EPSP amplitude was significantly larger in rats with previously axotomized LG-S nerves (Fig. $2 a ; F=11.1 ; p=$ $0.002)$. The observed mean percent increase (70\%) was comparable with that previously reported $3 \mathrm{~d}$ after muscle nerve section and confirms that the efficacy of monosynaptic excitation produced by group I LG-S afferent connections is increased by peripheral nerve axotomy (Miyata and Yasuda, 1988, see their Fig. 2a).

The increased EPSP amplitude consequent to axotomy was accompanied by a significant increase in negative modulation (-14\%) during $167 \mathrm{~Hz}$ stimulation (Table 1). EPSPs generated by stimulation of LG-S nerves axotomized $3 \mathrm{~d}$ previously showed
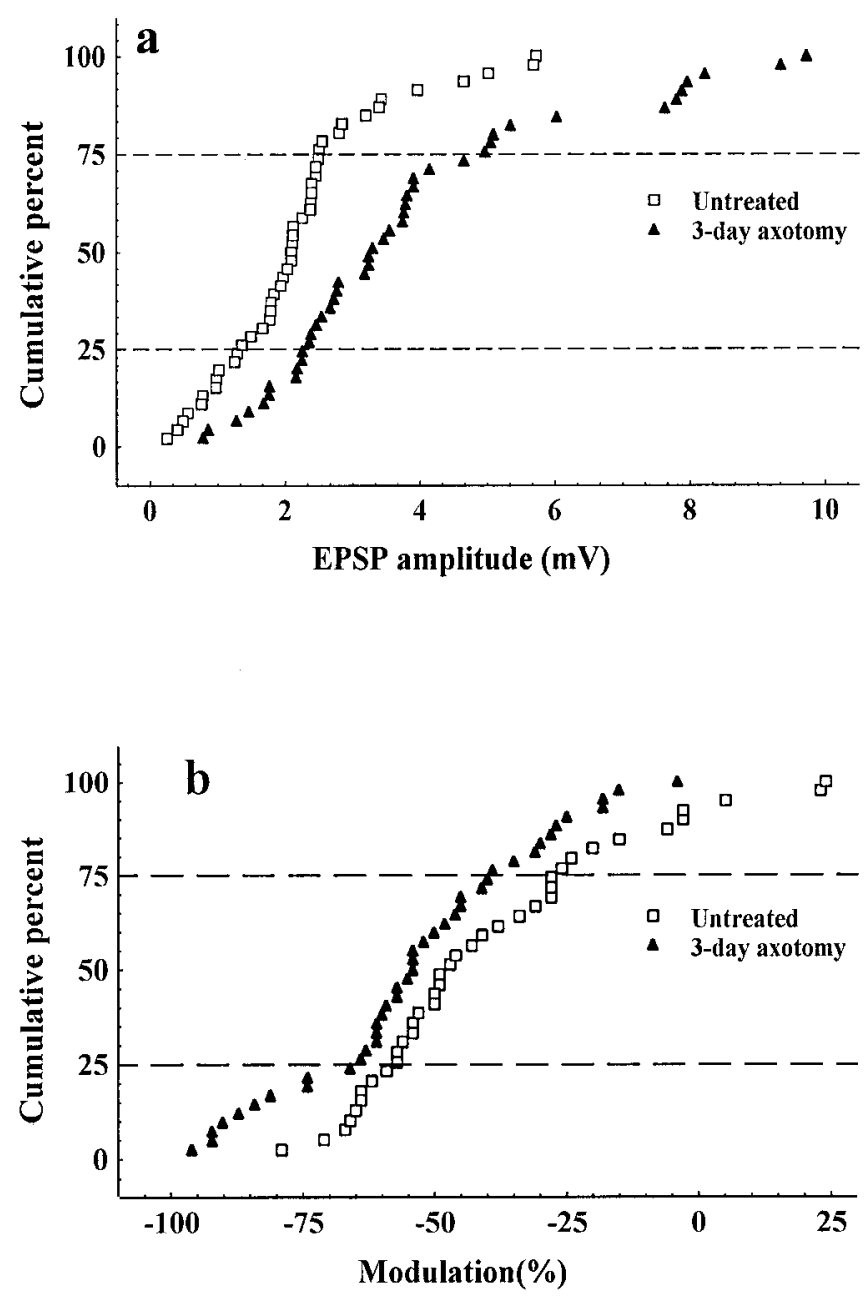

Figure 2. a, Cumulative histogram showing the increase in EPSP amplitude across the entire population of cells. $b$, Cumulative histogram showing the leftward shift in modulation $3 \mathrm{~d}$ after LG-S axotomy.

more negative modulation across the entire sample during highfrequency stimulation (Fig. $2 b ; F=4.9 ; p=0.04$ ). Also, as shown in Figure 3, the expected negative relationship between EPSP amplitude and modulation was confirmed for rats in both the untreated and experimental groups $(r=-0.37$ and -0.55 , un- 


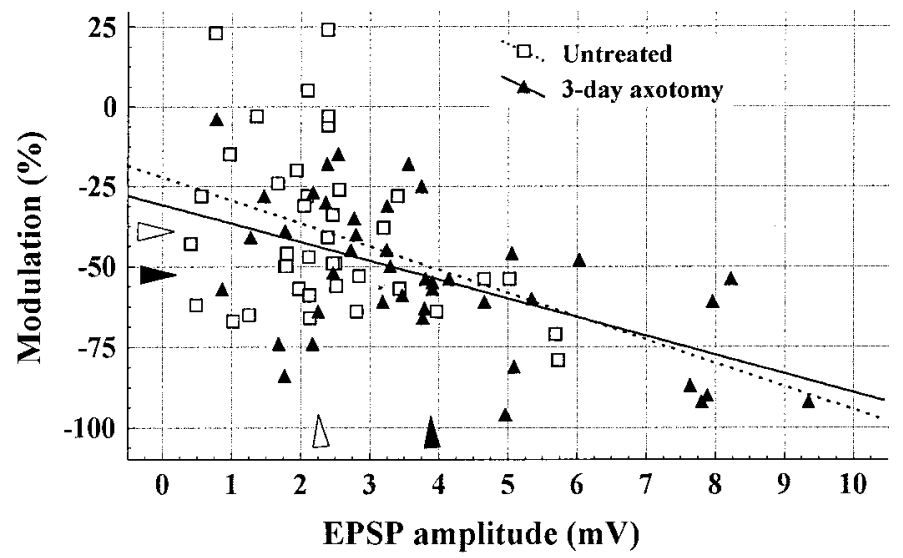

Figure 3. Scatterplot of heteronymous (LG-S) EPSP amplitude versus modulation (see Fig. 1e):

$167 \mathrm{~Hz}$ modulation $(\%)=100\left[\left[\frac{(\text { EPSP30 }+ \text { EPSP31 }) \div 2}{\text { EPSP1 }}\right]-1\right]$.

Open and filled arrows indicate mean values in untreated and axotomized rats, respectively. The linear correlation between amplitude and modulation was significant for both groups $(r=-0.37 ; p=0.02 ; n=39$; and $r=$ $-0.55 ; p<0.001 ; n=42$; untreated and $3 \mathrm{~d}$ axotomy, respectively).

treated and axotomy, respectively). The persistence of this relationship after axotomy suggests that the two variables changed in a coordinated manner. A similar result was found for $18 \mathrm{~Hz}$ modulation with significantly greater negative modulation of EPSPs produced by axotomized afferents (Table $1 ; F=5.2 ; p=0.03$ ).

We also examined the amplitude of EPSPs evoked $2 \mathrm{sec}(2 \mathrm{sec}$ post-train EPSP) and $100 \mathrm{msec}(0.1 \mathrm{sec}$ post-train EPSP) after the high-frequency burst (see Fig. 1e). These ratios have been used in previous studies to test for post-tetanic potentiation (Davis et al., 1985; Peshori et al., 1998). However, in our hands EPSP amplitude is not, on average, potentiated at either time point (Table 1), and indeed $\sim 50 \%$ of the sample is still slightly depressed relative to control (Fig. 4). This is the result of our use of EPSPs recorded at $0.5 \mathrm{~Hz}$ as our control EPSP amplitude. In previous studies using this stimulus paradigm in the cat (Collins et al., 1984; Davis et al., 1985; Koerber and Mendell, 1991; Mendell et al., 1995) and the rat (Peshori et al., 1998), control EPSP amplitude was determined at $18 \mathrm{~Hz}$ stimulation. Our preliminary observations (see Materials and Methods) showed that the use of EPSPs recorded at $18 \mathrm{~Hz}$ in the rat overestimates potentiation because it is an expression of the change from a significantly depressed state. Indeed, in the present study, the use of the $18 \mathrm{~Hz}$ EPSP amplitude as our control EPSP would have led us to report a significant increase in "potentiation" in cells contacted by axotomized afferents.

The mean values for post-train EPSPs were not significantly different between untreated and axotomized animals $(F=2.1$; $p=0.16$; and $F=3.5 ; p=0.07 ; 2$ and $0.1 \mathrm{sec}$, respectively) (Table 1). However, a slight leftward shift is evident in the distributions of both measures, indicating a trend toward greater post-train depression that is most apparent at the $100 \mathrm{msec}$ interval (Fig. 4). This trend is consistent with our findings for modulation and suggests that effects observed during the high-frequency stimulation persisted to a greater extent in cells contacted by axotomized afferents. We explored these observations further by examining the relationship between modulation and both post-train EPSP amplitude ratios. The relationship between modulation and the 2
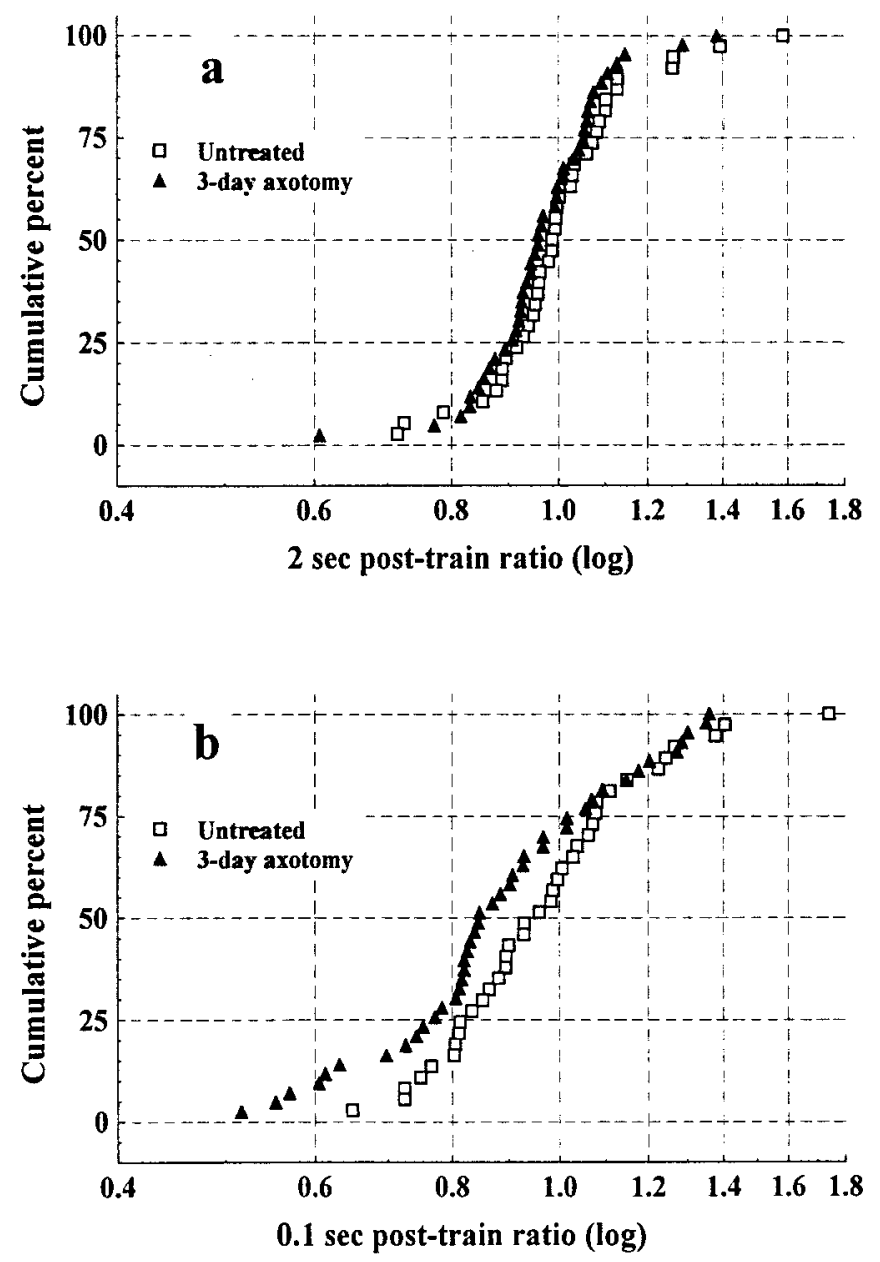

Figure 4. Cumulative histogram showing the relative change in EPSP amplitude $2 \mathrm{sec}$ after the $167 \mathrm{~Hz}$ stimulation (2 sec post-train ratio) (a) and $100 \mathrm{msec}$ after the $167 \mathrm{~Hz}$ stimulation ( $0.1 \mathrm{sec}$ post-train ratio) (b). Means for both ratios were not significantly different between untreated and axotomized groups (see Results).

sec post-train ratio was not significant for either group $(r=0.13$; $p=0.4$; and $r=0.25 ; p=0.1$; untreated and axotomy, respectively). However, the relationship between modulation and the $0.1 \mathrm{sec}$ post-train ratio was significant for both groups $(r=0.56$; $p<0.001$; and $r=0.78 ; p<0.001$; untreated and axotomy, respectively). Together these results suggest that the processes contributing to changes in EPSP amplitude during high-frequency stimulation (modulation) persist for at least $100 \mathrm{msec}$ but are no longer operating $2 \mathrm{sec}$ after the burst.

Two additional experiments were performed to determine the extent to which axotomy silenced afferent impulse conduction. Twenty-four hours after axotomy, only 9 of 75 afferents showed any activity, and only 6 of these 9 were presumptive group I or II afferents. Three days after nerve section, 18 of 75 were spontaneously active, and 15 of these 18 conducted at velocities within group I or II range. The level of spontaneous activity we observed is similar to previous work in the rat (Govrin-Lippmann and Devor, 1978). It has been estimated that muscle afferents comprise $\sim 20 \%$ of all sensory axons in the rat sciatic nerve (Swett et al., 1991). On this basis we estimate that, in the axotomized sciatic nerve, one to three of the spontaneously active afferents with CVs exceeding $40 \mathrm{~m} / \mathrm{sec}$ were group I or II muscle afferents 
(i.e., 20\% of 6-15). This suggests that the majority of the LG-S afferents in the sectioned LG-S nerve were silent during the $3 \mathrm{~d}$ period after LG-S nerve section.

\section{DISCUSSION}

This study confirms that peripheral nerve axotomy in the rat results in an initial increase in EPSP amplitude, or synaptic efficacy (Miyata and Yasuda, 1988), and extends this observation by the demonstration that it is accompanied by an increase in negative modulation during high-frequency stimulation (Figs. 1, 2). A conventional interpretation of these results is that the increase in efficacy is presynaptic in origin and is attributable, at least partly, to an increased probability of transmitter release at axotomized connections (Collins et al., 1984; Peshori et al., 1998). Thus, the present results also suggest that the probability of transmitter release at this synapse is regulated by afferent impulse activity and/or trophic support.

There are alternative explanations for the present results that are unlikely in our view but that cannot be definitively excluded. These include changes in connectivity, presynaptic inhibition, and postsynaptic receptor sensitization or desensitization. A change in connectivity could arise either from central sprouting or unmasking of previously silent connections (Wall, 1988; Koerber et al., 1994), and therefore an increase in the number of afferent connections over the time period studied here is possible. In axotomized motoneurons, any change in connectivity is undetectable electrophysiologically for at least $10 \mathrm{~d}$ and is reduced, not increased (Eccles et al., 1959; Mendell et al., 1976). To our knowledge, evidence of changes in connectivity of axotomized group I afferents onto intact motoneurons is unavailable at present. But regardless, as alluded to above, changes in connectivity alone would not be expected to alter modulation because connections made by different afferents onto the same motoneuron show similar patterns of modulation as do those of single afferent and composite EPSP recordings (Koerber and Mendell, 1991). A change in presynaptic inhibition also seems an unlikely explanation for the observed increase in EPSP amplitude. Indirect measures of presynaptic inhibition show no significant changes until $4 \mathrm{~d}$ or more after axotomy (Wall and Devor, 1981). Finally, although we attempted to exclude postsynaptic factors by recording from undamaged motoneurons, the available evidence does not allow evaluation of the potential contribution of postsynaptic receptor sensitization or desensitization to the present results.

The increased negative modulation that we report here is also present at longer times after axotomy. Mendell et al. (1995) reported significantly smaller EPSP amplitudes that were, contrary to expectation, accompanied by increased negative modulation. It was concluded that the decrease in EPSP amplitude could not, therefore, be attributed to decreased probability of release because such a change predicts less, not more, negative modulation (Peshori et al., 1998). A possible explanation for this discrepancy is provided by our demonstration that greater negative modulation is already present $3 \mathrm{~d}$ after axotomy. This result suggests that an initial axotomy-induced increase in the probability of transmitter release persists at connections that remain viable after chronic nerve section and is responsible for the enduring increase in negative modulation.

The majority of EPSPs measured in the present study showed little potentiation, suggesting that at the rat Ia-motoneuron synapse the processes leading to depression, such as transmitter depletion or availability, generally dominate those contributing to enhanced release after high-frequency stimulation (Fig. 4). The changes in EPSP amplitude after high-frequency stimulation are generally attributed to an increase in the probability of release because of a buildup of residual calcium (Kuno, 1964b; Hirst et al., 1981; Lev-Tov et al., 1983). However, the extent of potentiation is highly dependent on the stimulation protocol used. We did not do a systematic examination of different protocols, and it may be that higher frequency stimulation and/or EPSPs recorded at longer post-train intervals would have revealed further information. Nonetheless, our observation of a trend toward increased depression in post-train EPSP amplitude (Fig. 4) and the significant relationship between the $0.1 \mathrm{sec}$ post-train amplitude ratio and modulation further support our contention that axotomy induces an increase in the probability of release. These data also suggest a common mechanism for changes in EPSP amplitude that occur $100 \mathrm{msec}$ after the train and for those observed during the burst (modulation).

In considering the basis for the present results, we note that cutting afferents has two effects. One is that it greatly reduces the amount of afferent impulse traffic. The potential importance of afferent inactivity is established by the increase in EPSP amplitude caused when tetrodotoxin (TTX) is used to reversibly block impulse traffic in an intact peripheral nerve (Gallego et al., 1979; Manabe et al., 1989; Webb and Cope, 1992). The magnitude and time course of the increase in EPSP amplitude observed in the rat after TTX treatment and axotomy are very similar. On the basis of these comparisons, Manabe et al. (1989) suggested that the cause of the enhanced efficacy observed soon after axotomy is inactivity, a notion entirely consistent with our data. A second effect of axotomy is the separation of afferent cell bodies and central synapses from muscle-derived neurotrophic factors. The importance of these factors is emphasized by the recent results of Munson et al. (1997). They show that treatment of axotomized peripheral nerves with exogenous NT-3 produces a significant increase in the amplitude of EPSPs produced by treated-cut afferents. These results are inconsistent with the present findings and argue against a role for NT-3 in causing changes in transmission soon after axotomy. This argument is based on (1) the increase in EPSP amplitude that we observed despite the presumed loss of muscle-derived NT-3 and (2) the increase in negative modulation that we observed after axotomy was not observed after exogenous application of NT-3 (Munson et al., 1997). Thus, it seems unlikely that muscle-derived NT-3 alone is directly responsible for our results. However, a role for other trophic factors or combinations of factors cannot be ruled out and indeed seems likely, because when sectioned nerves are allowed to reinnervate their target muscle, both amplitude and modulation return toward normal values (Mendell et al., 1995).

A growing body of evidence points to the likely involvement of multiple factors in regulating synaptic function at the Ia-motoneuron synapse. For instance, NT-3 is associated with afferents, whereas BDNF and NT-4 are associated with motoneurons; all are produced in skeletal muscle and transported centrally, and they respond differentially to variations in muscle contractile activity (DiStefano et al., 1992; Funakoshi et al., 1993, 1995; Koliatsus et al., 1993; Yan et al., 1993; Copray and Brouwer, 1994). Finally, BDNF has recently been implicated in the regulation of motoneuron excitability (Gonzalez and Collins, 1997). Thus, it seems likely that these factors and perhaps others work in a coordinated manner to provide precise, activity-dependent control of synaptic function in the spinal cord. 


\section{REFERENCES}

Collins III WF, Honig MG, Mendell LM (1984) Heterogeneity of group Ia synapses on homonymous alpha-motoneurons as revealed by highfrequency stimulation of Ia afferent fibers. J Neurophysiol 52:980-992.

Collins III WF, Davis BM, Mendell LM (1986) Amplitude modulation of EPSPs in motoneurons in response to a frequency-train in single Ia afferents. J Neurosci 6:1463-1468.

Copray JCVM, Brouwer N (1994) Selective expression of neurotrophin-3 messenger RNA in muscle spindles of the rat. Neuroscience 63:1125-1135.

Davis BM, Collins III WF, Mendell LM (1985) Potentiation of transmission at Ia-motoneuron connections induced by rep short bursts of afferent activity. J Neurophysiol 54:1541-1552.

Del Castillo J, Katz B (1954) Statistical factors involved in neuromuscular facilitation and depression. J Physiol (Lond) 124:574-585.

Distefano PS, Friedman B, Radziejewski C, Alexander C, Boland P, Schick CM, Lindsay RM, Wiegand SJ (1992) The neurotrophins BDNF, NT-3, and NGF display distinct patterns of retrograde axonal transport in peripheral and central neurons. Neuron 8:983-993.

Dobrunz LE, Stevens CF (1997) Heterogeneity of release probability, facilitation, and depletion at central synapses. Neuron 18:995-1008.

Eccles JC, Krnjevic K, Miledi R (1959) Delayed effects of peripheral severance of afferent nerve fibres on the efficacy of their central synapses. J Physiol (Lond) 145:204-220.

Frank K, Fuortes MGF (1956) Stimulation of spinal motoneurones with intracellular electrodes. J Physiol (Lond) 134:451-470.

Funakoshi H, Frisen J, Barbany G, Timmusk T, Zachrisson O, Verge VMK, Persson H (1993) Differential expression of mRNA's for neurotrophins and their receptors after axotomy of the sciatic nerve. J Cell Biol 123:455-465.

Funakoshi H, Belluardo N, Arenas E, Yamamoto Y, Casabona A, Persson H, Ibanez CF (1995) Muscle-derived neurotrophin-4 as an activity-dependent trophic signal for adult motor neurons. Science 268:1495-1499.

Gallego R, Kuno M, Nunez R, Snider WD (1979) Disuse enhances synaptic efficacy in spinal motoneurones. J Physiol (Lond) 291:191-205.

Gardiner PF (1993) Physiological properties of motoneurons innervating different muscle unit types in rat gastrocnemius. J Neurophysiol 69:1160-1170.

Goldring JM, Kuno M, Nunez R, Snider WD (1980) Reaction of synapses on motoneurones to section and restoration of peripheral sensory connexions in the cat. J Physiol (Lond) 309:185-198.

Gonzalez M, Collins III WF (1997) Modulation of motoneuron excitability by brain-derived neurotrophic factor. J Neurophysiol 77:502-506.

Govrin-Lippmann R, Devor M (1978) Ongoing activity in severed nerves: source and variation with time. Brain Res 159:406-410.

Hirst GDS, Redman SJ, Wong K (1981) Posttetanic potentiation and facilitation of synaptic potentials evoked in cat spinal motoneurones. J Physiol (Lond) 321:97-110.

Kaizawa J, Takahashi I (1970) The low frequency depression of rat monosynaptic reflex. Tohoku J Exp Med 100:383-394.

Kang HJ, Schuman EM (1995a) Neurotrophin-induced modulation of synaptic transmission in the adult hippocampus. J Physiol (Paris) 89:11-22.

Kang HJ, Schuman EM (1995b) Long-lasting neurotrophin-induced enhancement of synaptic transmission in the adult hippocampus. Science 267:1658-1662.
Koerber HR, Mendell LM (1991) Modulation of synaptic transmission at Ia-afferent fiber connections on motoneurons during high-frequency stimulation: role of postsynaptic target. J Neurophysiol 65:590-597.

Koerber HR, Mirnics K, Brown PB, Mendell LM (1994) Central sprouting and functional plasticity of regenerated primary afferents. J Neurosci 14:3655-3671.

Koliatsos V, Clatterbuck R, Winslow J, Cayouette M, Price D (1993) Evidence that brain derived neurotrophic factor is a trophic factor for motor neurons in vivo. J Neurobiol 25:707-721.

Kuno M (1964a) Quantal components of excitatory synaptic potentials in spinal motoneurones. J Physiol (Lond) 175:81-99.

Kuno M (1964b) Mechanism of facilitation and depression of the excitatory synaptic potential in spinal motoneurones. J Physiol (Lond) 175:100-112.

Lev-Tov A, Pinter MJ, Burke RE (1983) Posttetanic potentiation of group Ia EPSPs: possible mechanisms for differential distribution among medial gastrocnemius motoneurons. J Neurophysiol 50:379-398.

Lewin GR, Barde Y-A (1996) Physiology of neurotrophins. Annu Rev Neurosci 19:289-318.

Lewin GR, McMahon SB (1991) Physiological properties of primary sensory neurons appropriately and inappropriately innervating skeletal muscle in adult rats. J Neurophysiol 66:1219-1231.

Manabe T, Kaneko S, Kuno M (1989) Disuse-induced enhancement of Ia synaptic transmission in spinal motoneurons of the rat. J Neurosci 9:2455-2461.

Mendell LM (1984) Modifiability of spinal synapses. Physiol Rev 64:260-316.

Mendell LM, Munson JB, Scott JG (1976) Alterations of synapses on axotomized motoneurones. J Physiol (Lond) 255:67-79.

Mendell LM, Taylor JS, Johnson RD, Munson JB (1995) Rescue of motoneuron and muscle afferent function in cats by regeneration into skin. II. Ia-motoneuron synapse. J Neurophysiol 73:662-673.

Miyata Y, Yasuda H (1988) Enhancement of Ia synaptic transmission following muscle nerve section: dependence upon protein synthesis. Neurosci Res 5:338-346.

Munson JB, Johnson RD, Mendell LM (1997) NT-3 increases amplitude of EPSPs produced by axotomized group Ia afferents. J Neurophysiol 77:2209-2212.

Peshori KR, Collins III WF, Mendell LM (1998) Mechanisms of frequency-dependent amplitude modulation at the rat Ia-alpha motoneuron synapse. J Neurophysiol, in press.

Seburn KL, Cope TC (1997) Low-frequency depression of the monosynaptic reflex is not altered by tetrodotoxin-induced nerve conduction blockade. J Neurophysiol 78:19-23.

Swett JE, Torigoe Y, Elie VR, Bourassa CM, Miller PG (1991) Sensory neurons of the rat sciatic nerve. Exp Neurol 114:82-103.

Wall PD (1988) Recruitment of ineffective synapses after injury. Adv Neurol 47:387-400.

Wall PD, Devor M (1981) The effect of peripheral nerve injury on dorsal root potentials and on transmission of afferent signals into the spinal cord. Brain Res 209:95-111.

Webb CB, Cope TC (1992) Modulation of Ia EPSP amplitude: the effects of chronic synaptic inactivity. J Neurosci 12:338-344.

Yan Q, Elliot J, Matheson C, Sun J, Zhang L, Mu X, Rex K, Snider W (1993) Influences of neurotrophins on mammalian motor neurons in vivo. J Neurobiol 24:1555-1577. 